\title{
Raji Cell Radioimmunoassay
}

National Cancer Institute

\section{Source}

National Cancer Institute. Raji Cell Radioimmunoassay. NCI Thesaurus. Code C135459.

A type of complement receptor-dependent immune complex assay that uses

radiolabeled anti-lgA, anti-IgG, or anti-IgM Raji cells to detect the presence of soluble immune complexes in biologic fluids. 